\title{
Response and Side Effects from Rheumatoid Arthritis Therapy at Dr. Soetomo General Hospital Surabaya 2017
}

\author{
Ayu Imamatun Nisa1 ${ }^{1}$, , Awalia Awalia ${ }^{2^{*}} \mathbb{D}$, Jusak Nugraha ${ }^{3}$
}

${ }^{1}$ Faculty of Medicine, Universitas Airlangga, Surabaya, Indonesia.

${ }^{2}$ Department of Internal Medicine, Faculty of Medicine, Universitas Airlangga/Dr. Soetomo General Hospital, Surabaya, Indonesia. ${ }^{3}$ Department of Clinical Pathology, Universitas Airlangga/Dr. Soetomo General Hospital, Surabaya, Indonesia.

\section{A B S T R A C T}

Introduction: Rheumatoid arthritis (RA) is an autoimmune disease which mainly attacks synovial membrane and causes systemic manifestation. During treatment, controlling disease activity is needed to prevent further complication. On the other hand, medications used in the treatment of RA may bring various side effects. It is important to evaluate side effects from the given therapy.

Methods: This study aimed to evaluate response and side effects of therapy in RA patients. The samples were collected from 59 RA patients at Rheumatology Division of Outpatient Clinic in Department of Internal Medicine Dr. Soetomo General Hospital Surabaya in 2017. This study method was descriptive observational with cross sectional design using medical records.

Results: Pain was reduced in $83.1 \%$ patients, Erythrocyte Sedimentation Rate (ESR) increased in 61.4\% patients, and C-Reactive Protein (CRP) decreased in 50\% patients. Based on the statistic analysis, ESR decreased significantly $(p=0.012)$ while CRP decreased not significantly $(p=0.415)$. The side effects were observed from clinical and laboratory data. Based on clinical symptoms, there were alopecia in $1.7 \%$ patient, dyspepsia in $78 \%$ patients, infection in $27.1 \%$ patients, and other symptoms including itchy skin, neuropathy, hyperuricemia, hyperkalemia and Acute Kidney Injury (AKI). Meanwhile, abnormalities in laboratory data include increased aspartate transaminase (AST) in $3.8 \%$ patients, increased alanine transaminase (ALT) in $26.1 \%$ patients, increased Blood Urea Nitrogen (BUN) in $7.9 \%$ patients, increased creatinine serum in $7.9 \%$ patients, decreased hemoglobin in $15.5 \%$ patients, and decreased leukocytes in $3.4 \%$ patients.

Conclusion: Most patients had a good therapeutic response based on decreased pain, while ESR had a significant decrease and CRP did not have significant decrease. Side effects discovered in patients were various.

\footnotetext{
*Correspondence: awalia_nov74@yahoo.com

JUXTA: Jurnal IImiah Mahasiswa Kedokteran Universitas Airlangga

p-ISSN: 1907-3623; e-ISSN: 2684-9453

DOI: $10.20473 /$ juxta.V13l12022.9-12

Open access under Creative Commons Attribution-ShareAlike 4.0 International License (CC-BY-SA)
}

ARTICLEINFO

Article history:

Received 18 October 2021

Received in revised form 21

December 2021

Accepted 24 December 2021

Available online 5 January 2022

\section{Keywords:}

Human \& disease,

Response of treatment,

Rheumatoid arthritis,

Side effects. 


\section{Introduction}

Rheumatoid arthritis (RA) is autoimmune disease with unknown etiology, marked by erosive synovitis, and in some cases involves extra articular organ. ${ }^{1}$ Previous studies have shown that RA contributed $4.1 \%$ of new cases in Rheumatology Clinic Dr. Cipto Mangunkusumo National Central Public Hospital Jakarta in 2000. ${ }^{1}$ In Hasan Sadikin Hospital, Bandung, 9\% from new rheumatic disease case in 2000-2002 were RA patients. ${ }^{1}$ Meanwhile, the crude prevalence of RA in China population was $0.41 \% .^{2}$ Extra articular manifestation is more likely to be found in patient with high rheumatoid factor titer, including rheumatoid nodule, vasculitis, complications in pulmonal, neurological, digestive, cardiovascular, skin, hematologic, and ocular. ${ }^{3}$ During treatment, controlling disease activity is needed to prevent further complication. Management for RA patients includes education, rehabilitation, pharmacotherapy, and surgery procedure. ${ }^{1}$ Main drug classes which are commonly used are nonsteroidal anti-inflammatory drugs (NSAID), disease-modifying antirheumatic drugs (DMARD), and corticosteroid. Those drugs are prescribed for patients in long term period. On the other hand, drugs used in the treatment of RA may bring various side effects.

NSAID has some adverse effects which include dyspepsia, peptic ulcer disease, and bleeding. ${ }^{4}$ More severe side effects that can be found include renal impairment, electrolyte and fluid abnormalities, bronchospasm, and aseptic meningitis. ${ }^{4}$ Corticosteroid can also cause facial flushing, fat atrophy, indentation and pigmentation in site injection, osteoporosis and skeletal fractures, gastrointestinal bleeding, peptic ulcer disease, diabetes mellitus, infections, cataracts, and impaired hypothalamic-pituitary-adrenal axis response. ${ }^{4}$ DMARD which is commonly used as first line agent in RA also has adverse effects. Methotrexate, one of DMARD drugs, can cause mouth ulcers, alopecia, rash, and increased rheumatoid nodule formation. ${ }^{4}$

This study aimed to evaluate response and side effects from RA therapy at Rheumatology Division of Outpatient Clinic in Department of Internal Medicine Dr. Soetomo General Hospital Surabaya in 2017.

\section{Methods}

This was a descriptive observational study using cross sectional design. This study was held in Rheumatology Division of Outpatient Clinic in Department of Internal Medicine Dr. Soetomo General Hospital Surabaya. The population for this study was RA patients who came to the hospital from 1 January to 31 December 2017. Then population of the patients was sorted into inclusion and exclusion criteria and categorized as sample with total sampling method. The inclusion criteria was RA patients in Rheumatology Division of Outpatient Clinic in Department of Internal Medicine Dr. Soetomo General Hospital Surabaya who came to the hospital from 1 January to 31
Desember 2017, had received pharmacotherapy (NSAID, DMARD, and corticosteroid) for 3-6 months, and did laboratory examination before treatment and 3-6 months after treatment.

This study used secondary data from medical records. In this study, dependent variables were gender, age, comorbid, and regimen therapy. The independent variables were therapeutic response, including pain and acute phase response (ESR and CRP), and side effects of therapy, including clinical status from medical record, AST, ALT, BUN, creatinine serum, hemoglobin, leukocyte, and thrombocyte. The collected data were analyzed using SPSS software. This study was approved by Ethic Committee of Dr. Soetomo General Hospital Surabaya.

\section{Results}

Table 1. Characteristics of the sample

\begin{tabular}{llll}
\hline Variable & Category & $\mathbf{n}$ & $\%$ \\
\hline \multirow{2}{*}{ Gender } & Male & 3 & 5.1 \\
& Female & 56 & 94.9 \\
\hline \multirow{4}{*}{ Age (years old) } & $16-25$ & 4 & 6.8 \\
& $26-35$ & 6 & 10.2 \\
& $36-45$ & 19 & 32.2 \\
& $46-55$ & 20 & 33.9 \\
& 56-65 & 8 & 13.6 \\
& $\geq 66$ & 2 & 6.8 \\
\hline Comorbid & Without comorbid & 34 & 57.6 \\
& Anemia & 2 & 3.4 \\
& Vertigo & 1 & 1.7 \\
& Panniculitis & 1 & 1.7 \\
& Erythema nodosum & 1 & 1.7 \\
& Diabetes & 2 & 3.4 \\
& Dyslipidemia & 2 & 3.4 \\
& Hypertension & 9 & 15.3 \\
& Nung Tuberculosis & 1 & 1.7 \\
& Natrium Diclofenac & 28 & 47.5
\end{tabular}




$\begin{array}{lll}\text { Mefenamic Acid } & 1 & 1.7 \\ \text { lbuprofen } & 11 & 18.6\end{array}$

According to Table 1, most of the sample was female (94.9\%). Highest age proportion was $46-55$ years old (33.9\%). Patients without comorbid had larger part in this study $(57.6 \%)$ than patients who had comorbid.
Hypertension was the most dominant comorbid condition $(15.3 \%)$. The patients were treated with 3 class of agents, including DMARD, corticosteroid, and NSAID. Most used drugs from each class were methotrexate (52.5\%), chloroquine (52.5\%), methylprednisolone (86.4\%), and natrium diclofenac $(47.5 \%)$.

Table 2. Response of therapy

\begin{tabular}{llll}
\hline Variable & Category & $\mathbf{n}$ & $\%$ \\
\hline Pain & Decreased & 49 & 83. \\
& Constant & 10 & 16.9 \\
\hline
\end{tabular}

\begin{tabular}{|c|c|c|c|c|c|c|c|c|c|c|}
\hline \multirow{2}{*}{$\begin{array}{l}\text { Acute } \\
\text { Phase } \\
\text { Reactant }\end{array}$} & & & & \multicolumn{2}{|c|}{ Mean \pm SD } & \multicolumn{2}{|c|}{ Range } & \multicolumn{2}{|c|}{ Med. } & \multirow{2}{*}{$\begin{array}{l}\text { Diff. of } \\
\text { mean }\end{array}$} \\
\hline & & & & Before & After & Before & After & Before & After & \\
\hline $\begin{array}{l}\text { ESR } \\
(\mathrm{mm} / \mathrm{h}) \\
\mathrm{p}=0.012\end{array}$ & $\begin{array}{l}\text { Decreased } \\
\text { Constant } \\
\text { Increased }\end{array}$ & $\begin{array}{l}20 \\
2 \\
35\end{array}$ & $\begin{array}{l}35.1 \\
3.5 \\
61.4\end{array}$ & $\begin{array}{l}60.09 \\
\pm 34.88 \\
(n=57)\end{array}$ & $\begin{array}{l}48.66 \\
\pm 28.57 \\
(n=58)\end{array}$ & $6-120$ & $6-120$ & 50 & 41 & -11.43 \\
\hline $\begin{array}{l}\text { CRP } \\
\text { (mg/dL) } \\
p=0.415\end{array}$ & $\begin{array}{l}\text { Decreased } \\
\text { Constant } \\
\text { Increased }\end{array}$ & $\begin{array}{l}3 \\
1 \\
2 \\
\end{array}$ & $\begin{array}{l}50 \\
16.7 \\
33.3 \\
\end{array}$ & $\begin{array}{l}6.89 \\
\pm 14.69 \\
(n=17)\end{array}$ & $\begin{array}{l}3.91 \\
\pm 11.51 \\
(n=13)\end{array}$ & $0.1-50$ & $0.1-42.12$ & 0.9 & 0.1 & -2.98 \\
\hline
\end{tabular}

Therapeutic response was observed in pain and acute phase reactant. The data was collected before treatment and after 3-6 months treatment. Based on Table 2, pain and CRP decreased in $83.1 \%$ and $50 \%$ patients. Meanwhile, ESR increased in 20 patients (35.1\%). ESR and CRP changes were analyzed by Paired T Test with SPSS Statistics 25 software. The test results were interpreted as significant difference statistically if $p$ value $\leq$ level of significance $(\propto=0.05)$. From the results, $P$ value for ESR and CRP were 0.012 and 0.415. Meanwhile, the difference of mean value showed that these two variables decreased. Therefore, it was clear that ESR decreased significantly and CRP decreased but not significant within 3-6 months treatment.

Table 3. Side effects of therapy

\begin{tabular}{|c|c|c|c|c|c|c|c|c|c|c|}
\hline Variable & 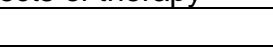 & $\mathbf{n}$ & $\%$ & & & & & & & \\
\hline \multirow[t]{8}{*}{ Clinical } & Alopecia & 1 & 1.7 & & & & & & & \\
\hline & Dyspepsia & 46 & 78 & & & & & & & \\
\hline & Infection & 16 & 27.1 & & & & & & & \\
\hline & Urinary tract & 7 & & & & & & & & \\
\hline & Respiratory tract & 5 & & & & & & & & \\
\hline & Leukhorrea & 1 & & & & & & & & \\
\hline & $\begin{array}{l}\text { Periodentitis and } \\
\text { pulp gangrene }\end{array}$ & 1 & & & & & & & & \\
\hline & $\begin{array}{l}\text { Stomatitis and } \\
\text { acne vulgaris } \\
\text { Others (itchy skin, } \\
\text { neuropathy, } \\
\text { hyperuricemia, } \\
\text { hyperkalemia, } \\
\text { Acute Kidney } \\
\text { Injury) }\end{array}$ & 2 & & & & & & & & \\
\hline \multirow[t]{2}{*}{ Laboratory } & & & & Mean \pm & & Range & & Med. & & $\begin{array}{l}\text { Diff. of } \\
\text { mean }\end{array}$ \\
\hline & & & & Before & After & Before & After & Before & After & \\
\hline $\begin{array}{l}\text { AST }(N=26, \\
U / L)\end{array}$ & $\begin{array}{l}\text { Normal } \\
\text { Mild hepatotoxic }\end{array}$ & $\begin{array}{l}25 \\
1 \\
\end{array}$ & $\begin{array}{l}96.2 \\
3.8\end{array}$ & $\begin{array}{l}25.88 \\
\pm 20.24\end{array}$ & $\begin{array}{l}21.74 \\
\pm 11.27\end{array}$ & $11-112$ & $11-77$ & 19 & 19 & -4.14 \\
\hline $\begin{array}{l}\text { ALT (N=23, } \\
\mathrm{U} / \mathrm{L})\end{array}$ & $\begin{array}{l}\text { Normal } \\
\text { Mild hepatotoxic }\end{array}$ & $\begin{array}{l}17 \\
6\end{array}$ & $\begin{array}{l}73.9 \\
26.1\end{array}$ & $\begin{array}{l}33.63 \\
\pm 36.31\end{array}$ & $\begin{array}{l}29.11 \\
\pm 15.83\end{array}$ & $9-235$ & $13-79$ & 23 & 24 & -4.51 \\
\hline $\begin{array}{l}\mathrm{BUN}(\mathrm{N}=35, \\
\mathrm{mg} / \mathrm{dL})\end{array}$ & Abnormal & 3 & 7.9 & $\begin{array}{l}11.27 \\
\pm 5.65 \\
\end{array}$ & $\begin{array}{l}10.81 \\
\pm 4.24 \\
\end{array}$ & $5-31$ & $3.4-4.4$ & 10 & 10 & -0.46 \\
\hline
\end{tabular}




\begin{tabular}{|c|c|c|c|c|c|c|c|c|c|c|}
\hline $\begin{array}{l}\text { Creatinine } \\
\text { Serum } \\
(\mathrm{N}=35 \\
\mathrm{mg} / \mathrm{dL})\end{array}$ & Grade 1 & 3 & 7.9 & $\begin{array}{l}0.78 \\
\pm 0.30\end{array}$ & $\begin{array}{l}0.80 \\
\pm 0.27\end{array}$ & $\begin{array}{l}0.34- \\
1.9\end{array}$ & $0.4-1.6$ & 0.7 & 0.74 & 0.02 \\
\hline $\begin{array}{l}\text { Hemoglobin } \\
(\mathrm{N}=58 \\
\mathrm{mg} / \mathrm{dL})\end{array}$ & $\begin{array}{l}\text { Grade } 1 \\
\text { Grade } 2\end{array}$ & $\begin{array}{l}7 \\
2\end{array}$ & $\begin{array}{l}12.1 \\
3.4\end{array}$ & $\begin{array}{l}12.36 \\
\pm 1.61 \\
\end{array}$ & $\begin{array}{l}10.81 \\
\pm 4.24 \\
\end{array}$ & $\begin{array}{l}7.2- \\
17.2\end{array}$ & $\begin{array}{l}7.8- \\
15.1\end{array}$ & 12.4 & 12.7 & 0.16 \\
\hline $\begin{array}{l}\text { Leukocyte } \\
(\mathrm{N}=58 \\
\left./ \mathrm{mm}^{3}\right)\end{array}$ & $\begin{array}{l}\text { Grade } 1 \\
\text { Grade } 3\end{array}$ & $\begin{array}{l}1 \\
1\end{array}$ & $\begin{array}{l}1.7 \\
1.7\end{array}$ & $\begin{array}{l}9174.48 \\
\pm 5773.26 \\
\end{array}$ & $\begin{array}{l}8343.22 \\
\pm 2500.04 \\
\end{array}$ & $\begin{array}{l}4600- \\
47100\end{array}$ & $\begin{array}{l}1217- \\
13160\end{array}$ & 8060 & 8080 & -831.26 \\
\hline $\begin{array}{l}\text { Thrombocyte } \\
(\mathrm{N}=57 \\
\left./ \mathrm{mm}^{3}\right)\end{array}$ & Normal & 57 & 100 & $\begin{array}{l}329.34 \\
\pm 107.79\end{array}$ & $\begin{array}{l}322.98 \\
\pm 89.28\end{array}$ & $\begin{array}{l}114- \\
602\end{array}$ & $\begin{array}{l}150- \\
592\end{array}$ & 314 & 325 & -6.36 \\
\hline
\end{tabular}

Side effects from the therapy was monitored by clinical condition and laboratory test. In Table 3, 78\% patients underwent dyspepsia during therapy. Interpretation for liver enzymes, creatinine serum, and blood count was based on Common Terminology Criteria for Adverse Events with normal value which is used at Dr. Soetomo General Hospital. Meanwhile, BUN level was determined as abnormal or normal. Patients who had incomplete data were not included. From the test result, abnormal AST and ALT were found in 1 patient (3.8\%) and 6 patients $(26.1 \%)$ which were then classified into mild hepatotoxic. 3 patients $(7.9 \%)$ had higher BUN level than normal cut off. Nephrotoxicity grade 1 was found in 3 patients $(7.9 \%)$ from creatinine serum. Hematological side effects including anemia grade 1 was found in 7 patients (12.1\%), anemia grade 2 in 2 patients (3.4\%), leukopenia grade 1 in 1 patient $(1.7 \%)$, and leukopenia grade 3 in 1 patient $(1.7 \%)$.

\section{Discussion}

\section{Gender Difference and Age Distribution in Rheumatoid Arthritis Patients}

RA has higher prevalence in female. Previous study in Indonesia showed that the prevalence of RA in female patient was 0.26 and male patient was $0.11 .{ }^{5}$ Similarly, a study in China showed that female RA patient dominated with prevalence of $0.46 \%$ while male prevalence was $0.08 \% .^{2}$ From the study, there were 5 male patients $(9.6 \%)$ and 47 female patients (90.4\%) with gender ratio 9.4:1. This study results showed higher gender ratio 18.7:1 from 56 female patients $(94.9 \%)$ and 3 male patients $(5.1 \%)$. This distinction may be affected with age distribution in patient. Female patients aged below 50 years old have higher RA incidence 4 to 5 times whereas patients aged 60 70 years old only have twice higher RA incidence. ${ }^{6}$

Age distribution in this study sample was dominated by 46-55 years old patients and the average age was 45.29 years old. This result is in line with previous studies in Egypt and Korea where the average age were 45 and 45.3 years old. 7,8 Another previous study in China pointed out the incidence of RA increased by age and mostly the patients were aged $\geq 66$ years old. ${ }^{2}$ The finding is contrary with this study which found that age range of 46-55 years old was dominant. Furthermore, studies in Brazil and Sweden showed that RA more often arose at young onset. ${ }^{9,10}$ It supports the result of this study which found that RA has higher proportion in younger age.

\section{Comorbid Condition in Rheumatoid Patients}

Comorbidities found in this study included hypertension (15.3\%), diabetes (3.4\%), dyslipidemia (3.4\%), hepatitis B (3.4\%), anemia (3.4\%), sleep disturbance $(3.4 \%)$, lung tuberculosis $(1.7 \%)$, vertigo (1.7\%), panniculitis (1.7\%), erythema nodosum (1.7\%), thyroid nodule $(1.7 \%)$, and hyperthyroid $(1.7 \%)$. This data partly correspond with a previous study in South Korea which reported that hypertension (30.3\%), osteoarthritis (22.6\%), dyslipidemia (14.1\%), and diabetes (12.9\%) were the most common comorbid found in RA patients. ${ }^{7}$ Other comorbidities included anemia, vertigo, panniculitis, erythema nodosum, or sleep disturbance were not reported in the Korean study. However, another study showed that anemia was frequently associated with RA with the prevalence at initial diagnosis as much as $15.9 \% .{ }^{11}$ Vertigo is also linked to RA through the audio vestibular system dysfunction and cochlear involvement which results in highfrequency hearing loss. ${ }^{12}$

Cervical involvement could be a rare complication of RA in the form of spine subluxation, either atlantoaxial subluxations, vertical subluxations, or sub axial subluxations. These conditions may cause cervical myelopathy and manifest as neurological symptoms which possibly involve brainstem in $0.2 \%$ patients, including nausea, vertigo, and drop attacks. ${ }^{13}$ Panniculitis is not manifested dominantly in RA patient. This condition is found in only $3.6 \%$ RA patients, compared to infection $(34.2 \%)$, ichtyotic skin $(27 \%)$, and pigmented purpuric dermatoses (14.4\%). ${ }^{14}$ Similar to panniculitis, erythema nodosum can not be found easily in RA patient. A previous study in Russia implied 15\% patients with panniculitis were diagnosed with rheumatic diseases and there were only 2 RA patients. ${ }^{15}$ Another condition that was associated with RA was sleep disturbance. It is supported with a study in Iran where $72 \%$ RA patient had poor sleep quality. ${ }^{16}$ There was a significant positive relationship between disease activity and sleep quality. ${ }^{17}$

\section{Anti-Rheumatic Drug Usage in Rheumatoid Arthritis Patients}

The most used DMARD were methotrexate (52.5\%) and chloroquine (52.5\%). Other drugs used in the treatment included sulfasalazine (40.7\%), cyclosporine (33.9\%), leflunamide $(6.8 \%)$, and azathioprine $(5.1 \%)$. Previous studies showed that DMARD as monotherapy included 
sulphasalazine (47.7\%), methotrexate (35.9\%), and hydroxychloroquine (16.4\%). ${ }^{18}$ Moreover, drug combination that was commonly prescribed were methotrexate and sulphasalazine (36.4\%), followed by methotrexate and hydroxychloroquine $(27.2 \%){ }^{18}$

Corticosteroid drugs prescribed for patients were methylprednisolone (85.4\%) and triamcinolone (14.6\%). Corticosteroid has been used widely in RA patients. Previous studies showed that low dose of oral prednisolone for RA patient decreased disease progression based on radiology finding. ${ }^{19}$ Intraarticular corticosteroid injection also gave improvement in RA patient. Patient with RA on knee had increasing extensor muscle strength and better clinical signs which included pain and range of motion. ${ }^{20}$

The most often prescribed NSAID were natrium diclofenac (47.5\%), mefenamic acid (1.7\%), and ibuprofen $(18.6 \%)$. As has been previously studied in Denmark, natrium diclofenac had more efficacies than ibuprofen regarded to consumption of analgesic, global evaluation, rheumatic activity, and activity index. ${ }^{21}$

\section{Therapeutic Response of Rheumatoid Arthritis Patients}

Therapeutic response was evaluated with American College of Rheumatology criteria which included patient assessment of pain. Pain should be assessed using Visual Analog Scale or Likert Scale. However, this study used objective complaint from the patients about their pain. $83.1 \%$ patients perceived less pain within 3-6 months of treatment. Improvement of pain was linked with disease activity and therapeutic response. Other studies implied that there was a correlation between pain, fatigue, and functional status which was reported by the patient with disease activity measurement using DAS $28 .{ }^{22}$

LED increased in $61.4 \%$ patients while CRP decreased in $50 \%$ patients. Based on the statistical analysis, ESR decreased significantly $(p=0.012$ ) while CRP decreased not significantly $(p=0.415)$. Aisde from therapeutic response, other factors such as age and gender could play a role. ESR and CRP increased by age, where ESR had the tendency to be higher in female patients. ${ }^{23}$ ESR had significant difference, although $61.4 \%$ patients had increasing ESR. It possibly happened due to the difference of increasing ESR value which was greater than decreasing ESR value. ESR and CRP did not become lower at the same time because CRP decreased faster than LED. ${ }^{24}$

\section{Side Effects of Therapy Rheumatoid Arthritis Patients}

Clinical side effects found in the patients were alopecia, dyspepsia, infection, itchytotic skin, neuropathy, hyperuricemia, hyperkalemia, and acute kidney injury (AKI). Dyspepsia was the most common side effect. Other studies showed that nausea and stomachache were found in $9.1 \%$ and $4.5 \%$ patients who received DMARD. ${ }^{18}$ Nausea may be caused by methotrexate, sulfasalazine, hydroxychloroquine, and leflunamide. ${ }^{4}$ Dyspepsia can occur during NSAID treatment. ${ }^{4}$
Methotrexate, hydroxychloroquine, and leflunamide can also cause alopecia. ${ }^{4}$ Alopecia is experienced in $9.8 \%$ patients who were given methotrexate and $16.6 \%$ patients who were given leflunamide during the first year of treatment. ${ }^{25}$ Skin rash can be caused by methotrexate, sulfasalazine, hydroxychloroquine, or leflunamide. ${ }^{4}$ Skin rash and itchy skin can be caused by leflunamide therapy. Those conditions were found in $12 \%$ patient. ${ }^{26}$ Infection can be found in patients who were treated with DMARD, corticosteroid, or anti TNF. Moreover, the incidence of the combination of corticosteroid and DMARD is up to $14.2 \%$ and DMARD is only up to $14.2 \% .{ }^{27}$

Neuropathy is commonly found in patients who were treated with leflunamide than methotrexate.28 Hyperuricemia may be caused by DMARD. Hyperkalemia and AKI can be caused by NSAID because NSAID affected kidney by inducing inflammation, altering water transport and Na-K balance. ${ }^{29}$

This study also found some side effects which were evaluated from laboratory data. This study used CTCAE from National Cancer Institute to classify the severity. There were 1 patient with mild hepatotoxic from AST level and 6 patients with mild hepatotoxic from ALT level. Other studies showed that increasing AST/ALT was found up to $40.9 \%$ from all side effect in patients with DMARD therapy. ${ }^{18}$ In line with the study, $47.9 \%$ patients who were given leflunamide had increasing transaminase enzymes. ${ }^{30}$ On the other hand, NSAID may play a role in which natrium diclofenac had the biggest proposition. ${ }^{31}$

Other side effect found in laboratory data was nephrotoxicity. In this study, abnormal BUN level in 3 patients and mild nephrotoxicity (grade 1 ) were based on creatinine serum found in 3 patients. RA patients had higher risk to chronic kidney disease and one of the contributing factors was NSAID therapy. ${ }^{32}$ DMARD may also play a role in nephrotoxity. Similarly, the incidence of increasing creatinine serum in patients with DMARD therapy was up to $4.4 \% .{ }^{33}$ According to hematology effects, there were anemia in 9 patients (15.5\%) and leukopenia in 2 patients (3.4\%). Prevalence of hematology toxicity in RA patients which included leukopenia, trombositopenia, anemia megaloblastic, and pancytopenia was estimated up to $2-4 \%{ }^{34}$ Previous studies showed that among 40 patients with low dose methotrexate, there were anemia grade 1 in $13.9 \%$ patients, anemia grade 2 in $25 \%$ patients, leukopenia grade 1 in $7.9 \%$ patients, and leukopenia grade 2 in $18.4 \%$ patients. $^{35}$

\section{Conclusion}

RA patients in Rheumatology Division of Outpatient Clinic in Department of Internal Medicine Dr. Soetomo General Hospital Surabaya 2017 were dominated by female and within the age of 46-55 years old. Most of the patients did not have comorbid. $42.4 \%$ patients had comorbid including hypertension (15.3\%), diabetes $(3.4 \%)$, dyslipidemia (3.4\%), hepatitis B $(3.4 \%)$, anemia $(3.4 \%)$, sleep disturbance (3.4\%), lung tuberculosis (1.7\%), vertigo 
(1.7\%), panniculitis (1.7\%), erythema nodosum (1.7\%), thyroid nodule $(1.7 \%)$, and hyperthyroid $(1.7 \%)$. The most used drugs from each class were methotrexate $(52.5 \%)$, chloroquine $(52.5 \%)$, methylprednisolone $(86.4 \%)$, and natrium diclofenac (47.5\%). Most patients (83.1\%) had a good therapeutic response based on decreased pain, while ESR ( $p$ value $=0.012$ ) had a significant decrease and CRP (0.415) did not have significant decrease. Clinical side effects found in the patients were alopecia, dyspepsia, infection, itchytotic skin, neuropathy, hyperuricemia, hyperkalemia, and AKI. Based on laboratory data, abnormal AST and ALT were found in 1 patient (3.8\%) and 6 patients $(26.1 \%)$ who were classified into mild hepatotoxic. 3 patients (7.9\%) had higher BUN level than normal cut off. Nephrotoxicity grade 1 was found in 3 patients $(7.9 \%)$ from creatinine serum. Hematological side effects including anemia grade 1 in 7 patients (12.1\%), anemia grade 2 in 2 patients (3.4\%), leukopenia grade 1 in 1 patient $(1.7 \%)$, and leukopenia grade 3 in 1 patient $(1.7 \%)$. Further research is needed on other factors that may interfere therapeutic response and side effect in patients. It is suggested to collect bigger sample and use objective measurement for pain such as Visual Analog Scale.

\section{CONFLICT OF INTEREST}

The author stated there is no conflict of interest in this study.

\section{REFERENCES}

1. Indonesian Rheumatology Association. Diagnosis \& Penatalaksanaan Artritis Reumatoid Perhimpunan Reumatologi Indonesia, https://reumatologi.or.id/rekomendasiperhimpunan-reumatologi-indonesia-reumatoidartritis-2014/ (2014).

2. Li R, Sun J, Ren LM, Wang HY, Liu WH, Zhang XW. Epidemiology of Eight Common Rheumatic Diseases in China: A Large-Scale Cross-Sectional Survey in Beijing. Rheumatology 2012; 51: 721729.

3. Cojocaru M, Cojocaru I, Silosi I, Vraibie CD, Tanasescu R. Extra-articular Manifestations of Rheumatoid Arthritis. Nauchno-Prakticheskaya Revmatol 2010; 5: 286-291.

4. Kumar P, Banik S. Pharmacotherapy Options in Rheumatoid Arthritis. Clin Med Insights Arthritis Musculoskelet Disord 2013; 6: 35-43.

5. Darmawan J, Muirden K., Valkenburg H., Wigley R.. The Epidemiology of Rheumatoid Arthritis in Indonesia. Rheumatology 1993; 32: 537-540.

6. Kvien T, Uhlig T, ØDEGÅRD S. Epidemiological Aspects of Rheumatoid Arthritis. Ann N Y Acad Sci 2006 1069: 212-222.

7. Jeong H, Baek SY, Kim SW, Eun YH, Kim IY, Kim H. Comorbidities of Rheumatoid Arthritis: Results from the Korean National Health and Nutrition Examination Survey. PLoS One 2017; 12: 1-15.

8. Elsaman A, Radwan A, Abou Dahab M, Sherif AM, AlFadl AM. AB0291 Epidemiology and Comorbidity of Rheumatoid Arthritis in Upper Egypt, a Hospital Based Study. Ann Rheum Dis; 76. Epub ahead of print 2017. DOI: 10.1136/annrheumdis-2017- eular. 1440.

9. Horiuchi AC, Pereira LHC, Kahlow BS, Silva MB, Skale TL. Rheumatoid arthritis in elderly and young patients. Rev Bras Reumatol (English Ed 2017; 57: 491-494.

10. Innala L, Berglin E, Möller B, Ljung L, Smedby $T$, Sodergren A. Age at Onset Determines Severity and Choice of Treatment in Early Rheumatoid Arthritis: A prospective study. Arthritis Res Ther 2014; 16: 1-9.

11. Rosner J, Mosheimer-Feistritzer B, Gruber J, Herold M, Mur E, Weiss G. FRI0083 Prevalence of Anemia in a Cohort of Rheumatoid Arthritis Patients- An Interim Analysis. Ann Rheum Dis; 74. Epub ahead of print 2015. DOI: 10.1136/annrheumdis-2015eular.2745.

12. El Dessouky TM, El Khair EA, Koura RA, El Sharkawy S. Assessment of The Audiovestibular System in Patients with Rheumatoid Arthritis. Egypt $J$ Otolaryngol 2017; 33: 650-655.

13. Zhang T, Pope J. Cervical Spine Involvement in Rheumatoid Arthritis Over Time: Results from a Meta-Analysis. Arthritis Res Ther 2015; 17: 1-9.

14. Ghosh S, Bandyopadhyay D, Biswas S, Darung I. Mucocutaneous Manifestations in Patients with Rheumatoid Arthritis: A Cross-Sectional Study from Eastern India. Indian J Dermatol 2017; 62: 411-417.

15. Karpova Y, Belov B, Egorova O. SAT0555 Erythema Nodosum in Rheumatology Clinic: A Study of 130 Cases. Ann Rheum Dis; 74. Epub ahead of print 2015. DOI: 10.1136/annrheumdis-2015eular.2352.

16. Abbasi M, Yazdi Z, Rezaie N. Sleep Disturbances in Patients with Rheumatoid Arthritis. Niger J Med 2013; 22: 181-186.

17. Westhovens R, Van Der Elst K, Matthys A, Tran M, Gilloteau I. Sleep Problems in Patients with Rheumatoid Arthritis. J Rheumatol 2014; 41: 3140.

18. Sulaiman W, Toib A, Chandrashekhar G, Arshad A. The trends of DMARDS Prescribed in Rheumatoid Arthritis Patients in Malaysia. Oman Med J 2009; 24: 260-263.

19. Kirwan J, The Arthritis and Rheumatism Council LowDose Glucocorticoid Study Group. The Effect of Glucocorticoids on Joint Destruction in Rheumatoid Arthritis. N Engl J Med 1995; 333: 142-6.

20. Geborek P, Månsson B, Wollheim F, Moritz U. Intraarticular Corticosteroid Injection into Rheumatoid Arthritis Knees Improves Extensor Muscles Strength. Rheumatol Int 1990; 9: 265270.

21. Meinicke J, Danneskiold-samsøe B. Diclofenac Sodium (Voltaren ${ }^{\circledR}$ ) and Ibuprofen in Rheumatoid Arthritis A Randomized Double-blind Study. Scand $J$ Rheumatol 1980; 9: 1-8.

22. Scharbatke EC, Behrens F, Schmalzing M, Khoem M, Greger G, Gnann H. Association of Improvement in Pain With Therapeutic Response as Determined by Individual Improvement Criteria in Patients With Rheumatoid Arthritis. Arthritis Care Res 2016; 68: $1607-1615$

23. Siemons L, Ten Klooster PM, Vonkeman HE, van Riel $P$, Glas $C$ van de M. How Age and Sex Affect The Erythrocyte Sedimentation Rate and C-reactive Protein in Early Rheumatoid Arthritis. BMC Musculoskelet Disord 2014; 15: 1-7. 
24.Murav'ev I V, Gridneva G, Karateev D, Luchikhina EL, Omonin luL, Aleksandrova EN. Evaluation of Methotrexate Effect on The Acute-Phase Response in Rheumatoid Arthritis after 12-week Treatment. Klin Med (Mosk) 2014; 92: 59-63.

25. Emery P, Breedveld FC, Lemmel EM, Kaltwasser JP, Dawes PT, Gomor B. A Comparison of The Efficacy and Safety of Leflunomide and Methotrexate for The Treatment of Rheumatoid Arthritis. Rheumatology 2000; 39: 655-665.

26. Jones PBB, White DHN. Reappraisal of The Clinical Use of Leflunomide in Rheumatoid Arthritis and Psoriatic Arthritis. Open Access Rheumatol Res Rev 2010; 2: 53-71.

27. Germano V, Cattaruzza MS, Osborn J, Tarantino A, Di Rosa R, Salemi S. Infection Risk in Rheumatoid Arthritis and Spondyloarthropathy Patients under Treatment with DMARDs, Corticosteroids and TNF- $\alpha$ antagonists. J Trans/ Med 2014; 12: 1-10.

28. Bharadwaj A, Haroon N. Peripheral Neuropathy in Patients on Leflunomide. Rheumatology 2004; 43: 934.

29. Hörl WH. Nonsteroidal Anti-Inflammatory Drugs and The Kidney. Pharmaceuticals 2010; 3: 2291-2321.

30. Razak SA, Islahudin F, Shamsuddin AF, Islahudin F, Shahri NS. A Study on Leflunomide-Induced Liver Injury in Rheumatoid Arthritis Patients. Res $J$ Pharm Technol 2013; 6: 556-561.
31.Sriuttha P, Sirichanchuen B, Permsuwan U. Hepatotoxicity of Nonsteroidal Anti-Inflammatory Drugs: A Systematic Review of Randomized Controlled Trials. Int J Hepatol; 2018. Epub ahead of print 2018. DOI: 10.1155/2018/5253623.

32. Chiu HY, Huang HL, Li CH, Chen HA, Yeh L, Chiu SH. Increased Risk of Chronic Kidney Disease in Rheumatoid Arthritis Associated with Cardiovascular Complications - A national population-based cohort study. PLOS One 2015; 10: $1-13$.

33. Karstila K, Rantalaiho V, Mustonen J, Mottonen TT, Hannonen PJ, Leirisalo-Repo M. Renal Safety of Initial Combination versus Single DMARD Therapy in Patients with Early Rheumatoid Arthritis: an 11year Experience from The FIN-RACo Trial. Clin Exp Rheumatol 2019; 28: 73-8.

34. Gutierrez-Ureña S, Molina J, García C, Cuellar ML, Espinoza LR. Pancytopenia Secondary to Methotrexate Therapy in Rheumatoid Arthritis. Arthritis and Rheumatism. Arthritis Rheum 1996; 39: 272-6.

35. Mori S, Hidaka M, Kawakita T, Hidaka T, Tsuda H, Yoshitama T. Factors associated with myelosuppression related to low-dose methotrexate therapy for inflammatory rheumatic diseases. PLoS One 2016; 11: 1-13. 